\title{
Refinamento de modelos de navegação de robôs autônomos através da calibração do sistema de odometria
}

\author{
Rafael da P. Cândido ${ }^{1}$, Gina M. B. de Oliveira ${ }^{1}$, Luiz G. A. Martins ${ }^{1}$ \\ ${ }^{1}$ Faculdade de Computação \\ Universidade Federal de Uberlândia (UFU) - Uberlândia, MG - Brazil \\ rcandidopegmail.com, \{gina, lgamartins\}eufu.br
}

\begin{abstract}
Bio-inspired techniques have been investigated in route planning in autonomous robot navigation models. Among these techniques, cellular automata (ACs) were shown to be a decentralized and low computational cost option. From the study of navigation models based on previously published ACs, it was noticed that the use of environments formed by cells of the size of the e-puck robot results in trajectories with collisions. In this work, a method of odometry calibration was integrated to these models of navigation in order to guarantee a more accurate trajectory. Simulations showed that the adopted method was able to improve the trajectorie in the scenario evaluated. The robot not only got closer to the goal cell, but also presented a path closer to the ideal and totally free of collisions.
\end{abstract}

Resumo. Técnicas bio-inspiradas têm sido investigadas no planejamento de rotas em modelos de navegação de robôs autônomos. Dentre essas técnicas, os autômatos celulares (ACs) se mostraram uma opção descentralizada e de baixo custo computacional. A partir do estudo de modelos de navegação baseado em ACs publicados previamente, percebeu-se que o uso de ambientes formados por células do tamanho do robô e-puck resulta em trajetórias com colisões. Neste trabalho, um método de calibração da odometria foi integrado a esses modelos a fim de garantir uma trajetória mais precisa. Simulações mostraram que o método adotado foi capaz de melhorar a trajetória no cenário avaliado. O robô não só chegou mais próximo da célula objetivo, como também apresentou uma trajetória mais próxima da ideal e totalmente livre de colisões.

\section{Introdução}

Na robótica, um mecanismo para determinar o posicionamento dentro do ambiente a ser navegado é a odometria, que é um dos métodos mais amplamente utilizados para estimar a posição de um robô durante sua navegação, pois sua aplicação fornece informações de maneira simples e acessível [Borenstein and Feng. 1994]. A ideia fundamental da odometria é a integração da informação incremental do movimento das rodas ao longo do tempo, o qual envolve um inevitável acúmulo de erros provenientes do ambiente e da base robótica. Esses acúmulos causam grandes erros na estimativa da posição, os quais aumentam proporcionalmente com a distância percorrida pelo robô. Apesar dessas limitações, muitos pesquisadores concordam que a odometria é uma parte importante do sistema de navegação de um robô, e que deve ser utilizada em conjunto com métodos de posicionamento absoluto (como o GPS) para proporcionar uma estimativa de posição mais confiável. 
Devido à sua natureza discreta, sua arquitetura descentralizada e sua capacidade para representar fenômenos complexos, os autômatos celulares (ACs) têm sido utilizados no desenvolvimento de vários modelos de navegação [Tzionas et al. 1997, Marchese 2002, Ioannidis et al. 2008, Akbarimajd and Hassanzadeh 2011, Ferreira et al. 2014, Lima and Oliveira 2017]. Neste artigo são estudados os modelos baseados na difusão de distâncias por ACs, mais especificamente as implementações para um único robô apresentadas em [Behring et al. 2000] e [Oliveira et al. 2015]. A tarefa do robô é determinar a melhor trajetória entre as posições atual (célula inicial) e desejada (célula objetivo), sem colidir com os obstáculos existentes no ambiente. Para isso, esse tipo de modelo precisa conhecer previamente o ambiente a ser navegado, a fim de identificar as posições dos obstáculos, do robô e da célula objetivo. Um sistema de odometria é utilizado de modo que o robô possa fazer uma estimativa de sua localização durante a navegação pelo ambiente. Entretanto, nas simulações com os modelos implementados ([Behring et al. 2000] e [Oliveira et al. 2015]), um erro considerável foi verificado, retornando trajetórias não apropriadas para a navegação. Neste trabalho implementamos um sistema de calibração baseado no método University of Michigan Benchmark test (UMBMark) [Borenstein and Feng. 1994], capaz de determinar valores aceitáveis para as principais fontes de incerteza nos cálculos de odometria. O objetivo é obter uma estimativa mais precisa da posição do robô e, consequentemente, melhorar sua trajetória. O modelo calibrado foi avaliado considerando a navegação de robôs e-puck em ambientes simulados no software. Os resultados indicam que o sistema de calibração foi capaz de reduzir a amplitude dos erros de odometria, garantindo a obtenção de uma trajetória mais precisa e livre de colisões em todos os cenários e modelos utilizados.

\section{Autômatos Celulares e Planejamento de Rotas}

Autômatos Celulares (ACs) são sistemas dinâmicos totalmente discretos compostos por componentes simples com interações locais. Basicamente, um AC consiste em duas partes: o espaço celular e a regra de transição. O espaço celular é um quadrilátero regular com dimensão $D$ de $N$ células, sendo cada com um idêntico padrão de conexões locais com outras células. Os Autômatos Celulares são caracterizadas por uma regra de transição que determina qual será a próxima configuração da rede a partir de seu estado atual. Assim, as células interagem localmente em um tempo discreto $t$, onde o estado da célula $i$ no tempo $t+1$ depende apenas dos estados de sua vizinhança no tempo $t$, incluindo a célula $i$, de modo que a atualização das células é geralmente realizada de uma maneira síncrona. Considerando as redes bidimensionais, as vizinhanças espaciais foram analisadas considerando a vizinhança de Moore, a qual é composta pela célula central e seus oito vizinhos imediatos (Sarkar, 2000). Portanto, ACs são sistemas espacialmente descentralizados, com um grande número de componentes conectados localmente, de modo que esses sistemas são capazes de desempenhar funções complexas com alto grau de robustez e eficiência, tal como o comportamento de um modelo ou sistema natural complexo. $\mathrm{O}$ planejamento de rotas para robôs autônomos busca encontrar uma sequência de passos a serem aplicados para se obter o melhor caminho, ou a rota ótima, entre o ponto inicial e a célula objetivo. Sendo que para determinado caso o conceito de melhor caminho está associado ao caminho mais rápido, ao mais curto, ou àquele que minimiza a quantidade de giros e/ou frenagens. Nesse contexto, os algoritmos de planejamento precisam conhecer previamente o ambiente a ser navegado. 


\section{Modelos de Navegação Investigados}

Recentemente, vários modelos baseados em ACs têm sido utilizados no planejamento de rotas [Shu and Buxton 1995, Behring et al. 2000, Marchese 2002, Parker et al. 2003, Ioannidis et al. 2011, Oliveira et al. 2015]. Neste artigo, são investigados os modelos de navegação propostos em [Behring et al. 2000] e [Oliveira et al. 2015], os quais seguem uma abordagem de difusão de distâncias baseada em ACs com o objetivo de encontrar a melhor rota para um robô autônomo navegando em um espaço de topologia planar [Marchese 1996]. Nessa abordagem, o ambiente possui obstáculos fixos e todas as informações sobre o espaço necessárias à navegação são conhecidas previamente. $\mathrm{O}$ espaço físico é representado por um plano bidimensional dividido em $n \times m$ células, de acordo com a resolução desejada. O robô ocupa uma célula do reticulado, correspondente à posição do centro cinemático do robô e sua orientação pode ser em 8 direções (norte, sul, leste, oeste, nordeste, noroeste, sudeste e sudoeste). A atualização das células do reticulado é feita de modo síncrono e é baseada na vizinhança de Moore (vizinhança composta pela célula central e suas 8 células adjacentes no plano). $O$ estado de cada célula do reticulado é representado pela seguinte estrutura: Obstáculo: define se a célula é livre de obstáculo (valor 0), se foi identificado um obstáculo na posição (valor $n$ ), ou se a célula está próxima a um obstáculo (valor entre 1 e $n-1$, sendo que quanto mais próximo, maior é o valor). Posição inicial: variável lógica que indica se é a posição inicial (verdadeiro) ou não (falso). Meta: variável lógica que indica se a posição é a meta buscada (verdadeiro) ou não (falso). Atributo de Atração: indica a distância mínima até a célula meta, de acordo com a direção do robô na célula, para as células que não são obstáculos. Próxima direção: equivale à indicação de qual é a próxima direção a seguir, caso o robô esteja na célula.

O robô deve partir de uma posição inicial referenciada no reticulado, percorrer o ambiente e atingir uma célula denominada objetivo da melhor maneira possível (percorrer a menor distância e no menor tempo). No modelo descrito em [Behring et al. 2000], a navegação do robô é baseada em um algoritmo de difusão de distância que é dividido em fases. Inicialmente, é realizado um alargamento dos obstáculos identificados no reticulado a fim de evitar uma possível colisão do robô durante sua trajetória. O processo de alargamento consiste da ampliação das dimensões do obstáculo real para algumas células vizinhas, criando uma área de segurança ao seu redor. O número de células correspondentes ao obstáculo alargado é um parâmetro a ser escolhido no algoritmo. Isso é feito para evitar que o robô atinja a quina de um obstáculo real quando fizer alguma conversão. A ideia é que o robô navegue pelo ambiente sem invadir as áreas de segurança dos obstáculos. Após o alargamento, é realizada a difusão das distâncias em relação à célula objetivo, ou seja, é determinado o quão distantes estão todas células do reticulado da célula objetivo. Assim, se uma célula está a uma distância $v$ do objetivo, então suas células livres vizinhas que ainda não têm valor atribuído estão a uma distância $v+1$. A Figura 1 ilustra a difusão das distâncias e planejamento de rotas. As células em preto representam os obstáculos, as brancas são células livres e as cinzas indicam, respectivamente, a posição do robô (I) e a célula objetivo $(\mathrm{G})$. A numeração em cada célula corresponde a sua distância até a célula objetivo. A Figura 1(a) demonstra o mapeamento do ambiente a ser navegado (reticulado) após a difusão das distâncias. A Figura 1(b) apresenta o caminho escolhido de acordo com as distâncias registradas em cada célula.

A abordagem proposta em [Oliveira et al. 2015] é uma evolução do modelo an- 


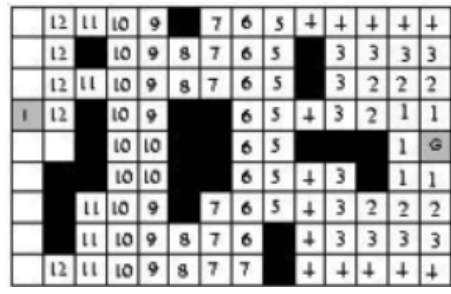

(a) Difusão das distâncias

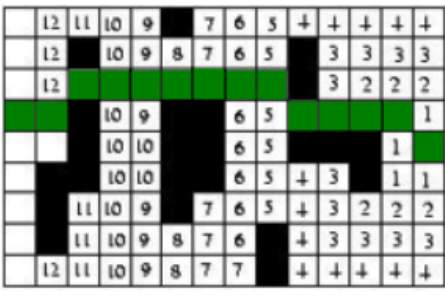

(b) Caminho encontrado

Figura 1. Exemplo de planejamento de rotas

terior ([Behring et al. 2000]), na qual a rota é recalculada a cada $n$ passos do robô. Essa estratégia visa reduzir o erro final do robô em relação a célula objetivo. Esse erro final é resultante dos erros de odometria acumulados que foram observados durante as simulações em diversos cenários avaliados. No novo modelo, as distâncias de cada célula livre em relação ao objetivo é recalculada após um determinado número de passos do robô. Em cada recálculo, a posição inicial do robô é diferente daquela considerada anteriormente, uma vez que o mesmo se deslocou pelo ambiente, e um novo caminho é definido, reduzindo o erro entre a posição final do robô e a célula objetivo. Além do recálculo, o modelo também foi adaptado para tratar os casos em que o robô está cercado por obstáculos alargados, ou se encontra em uma célula livre, mas a única alternativa para chegar ao objetivo seria passar por uma área alargada. No modelo inicial, quando alguma dessas situações ocorrem, a célula onde está o robô não é atingida pela difusão da distância e a rota é considerada inexistente. Essa situação é mais crítica quando há a realização do recálculo, e a nova posição do robô é uma célula alargada devido aos erros de odometria acumulados durante o percurso. Nessa abordagem, duas novas medidas foram integradas ao modelo como sub-estados das células alargadas. Uma medida para determinar a distância entre a célula que está em uma área de alargamento e a célula livre mais próxima. A outra medida quantifica o quão próxima cada célula das regiões alargadas está de um obstáculo. Essas medidas são calculadas através de dois novos ACs. Com essa intervenção busca-se que o robô saia rapidamente da área alargada para uma célula livre, bem como passe o mais distante possível do obstáculo que originou o alargamento.

\section{Modificações Implementadas}

A primeira alteração realizada nos modelos investigados refere-se ao tamanho das células do reticulado. Nos modelos originais, o ambiente a ser navegado é mapeado em um reticulado com células de 14 centímetros. Considerando que os obstáculos são alargados em uma célula ao seu redor para formar uma área de segurança, a navegação pelo ambiente fica restrita a regiões onde os obstáculos estejam distantes entre si por 42 centímetros. Dado que o diâmetro de um robô e-puck é de 7 centímetros, a área necessária entre os obstáculos para que haja um caminho possível corresponde a seis vezes o seu tamanho. Com o intuito de reduzir essa restrição, optou-se por utilizar células com o mesmo tamanho do diâmetro do robô $(7 \mathrm{~cm})$. Assim, é possível discretizar mais o ambiente, permitindo a navegação por regiões mais estreitas e complexas.

Apesar de refinar a navegabilidade do robô, durante as simulações com o novo reticulado, observou-se a ocorrência de colisões, invasão das áreas de segurança e/ou divergência entre as trajetórias realizada e planejada (robô perdido). Essa alteração de 
comportamento ocorre porque, com a redução na dimensão das células e, consequentemente, das áreas de segurança em torno dos obstáculos, o modelo é mais susceptível à falhas em função dos erros de odometria. Assim, com o objetivo de melhorar o sistema de odometria dos modelos de navegação, foi adotado o método de calibração University of Michigan Benchmark test (UMBMark) [Borenstein and Feng. 1994]. O método UMBMark é um processo sistemático de calibração da odometria de um robô de tração diferencial, de forma a compensar o efeito dos erros sistemáticos. Esses erros são causados por imperfeições físicas e mecânicas de um robô móvel. No trabalho desenvolvido por [Borenstein and Feng. 1994], observou-se que as duas fontes de erros sistemáticos mais notórios são os diâmetros desiguais das rodas e a incerteza sobre a distância entre rodas. Uma variação nesses valores ocasionará uma trajetória bastante diferente da ideal, e por isso devem ser calibrados. Dessa forma, pretende-se obter com isso os valores dos diâmetros das duas rodas e a distância entre rodas corrigidos. A maioria dos robôs móveis usa pneus de borracha para melhorar a tração. Estes pneus são difíceis de fabricar exatamente com o mesmo diâmetro. Além disso, pneus de borracha comprimem de forma diferente sob distribuição de carga assimétrica. Qualquer um desses efeitos pode causar erros substanciais de contagem decrescente. A distância entre eixos é definida como a distância entre pontos de contato das duas rodas motrizes de um robô de disco diferencial com o chão. A distância entre eixos deve ser conhecida para calcular o número de pulsos do codificador diferencial que correspondem a uma certa rotação do robô. A incerteza na distância entre rodas é causada pelo fato de que os pneus de borracha contatam o chão não em um ponto, mas em uma área de contato. Nesse sentido, nesse processo de calibração, foram calculados os valores para a base do robô e para diâmetros das rodas esquerda e direita. Além dos erros construtivos do robô, é importante citar o efeito das aproximações no erro da odometria, visto que ainda que o robô tivesse uma geometria perfeita, ainda haveria um erro de posição final após longas distâncias, em virtude da aproximação da constante $\pi$.

\section{Simulações e Resultados}

A fim de avaliar a influência do método de calibração UMBMark na qualidade das trajetórias resultantes dos modelos investigados, experimentos foram executados considerando a navegação de um robô e-puck em cenários (ambientes) implementados na plataforma de simulação Webots. A configuração dos cenários (posicionamento dos obstáculos, robô e célula objetivo) foi determinada de modo a exigir várias rotações durante a trajetória do robô. Essa decisão é baseada em experimentos prévios, nos quais percebeu-se que os erros da odometria são potencializados por movimentos de rotação.

Nos experimentos feitos, dois correspondem às implementações originais dos modelos propostos em [Behring et al. 2000] e [Oliveira et al. 2015], enquanto que as outras duas são variações desses modelos utilizando o método UMBMark para a calibração da odometria. Como o objetivo é avaliar a influência do método de calibração da odometria, as análises de desempenho foram agrupadas em função dos modelos de navegação. A Figura 2(a) mostra o cenário utilizado nas simulações das abordagens. Ele é formado por um reticulado bidimensional dividido em 9 x 18 células. Os obstáculos e a célula objetivo são representados pelas células pretas e vermelha, respectivamente. Nesta figura também é possível observar a trajetória ideal (desejada) do robô, a qual está destacada em vermelho. Para medir a eficiência das abordagens, adotou-se como métricas de desempenho o 
erro de posição final e o número de ocorrências de colisão na trajetória do robô. O erro de posição final é a distância entre a posição final do centro do robô, após o percorrimento da trajetória, e o ponto central da célula objetivo.

A Figura 2 mostra os resultados obtidos nas simulações com as duas abordagens baseadas no modelo proposto em [Behring et al. 2000]: modelo de navegação original e sua variação utilizando o método de calibração UMBMark. As células cinzas representam as áreas de segurança, decorrentes do alargamento de uma célula ao redor dos obstáculos, enquanto que a linha preta representa a trajetória realizada pelo robô. Em uma navegação ideal, as áreas de segurança não deveriam ser invadidas pelo robô. Entretanto, como pode ser observado na simulação do modelo original (Figura 2(b)), os erros acumulados de odometria durante a trajetória provocam não só a invasão dessas áreas, como também a colisão do robô com vários obstáculos (indicado pelas setas amarelas). Devido às colisões, o robô se perde e não consegue atingir a célula alvo. Esse comportamento era esperado, uma vez que o planejamento da rota é realizado uma única vez no início do processo. Dessa forma, todo o esforço para manter a trajetória do robô em conformidade com a rota definida inicialmente é baseado nas respostas do sistema de odometria. Portanto, a navegação do robô é mais susceptível aos erros de odometria. A Figura 2(c) mostra a trajetória obtida a partir do modelo que adota o método de calibração $U M B$ Mark. Nessa simulação, o robô percorre uma distância de 2,05 metros em 2 minutos e 3 segundos. Apesar de apresentar duas invasões das áreas de segurança e um erro final de posicionamento de 5,1802 centímetros, a trajetória resultante é livre de colisões e o robô consegue alcançar a célula objetivo.

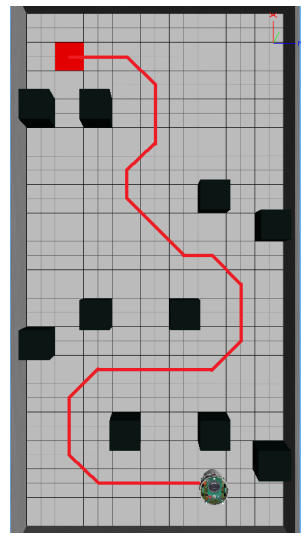

(a) Rota ideal

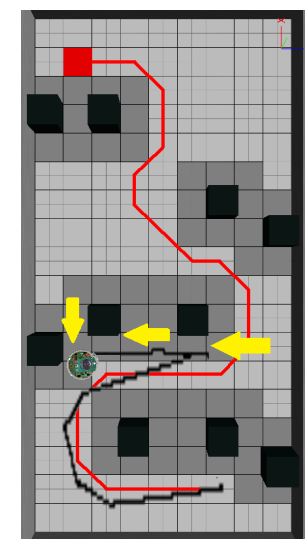

(b) Modelo original

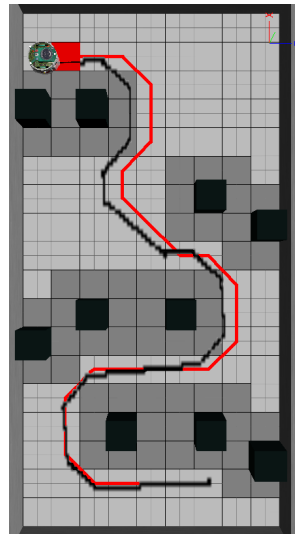

(c) Modelo refinado

Figura 2. Simulações baseadas no modelo proposto em [Behring et al. 2000].

Com o intuito de tornar a navegação mais adaptável, também foram implementadas duas abordagens baseadas no modelo proposto em [Oliveira et al. 2015]: modelo original e sua variação com o método de calibração UMBMark. Esse modelo adota um mecanismo de recálculo da trajetória periódico, o qual define uma nova rota a cada $n$ passos do robô. As trajetórias resultantes da simulação dessas duas abordagens é ilustrada na Figura 3. O número de passos para o recálculo depende da configuração do reticulado utilizado (das dimensões do ambiente e do caminho que deve ser percorrido pelo robô). Conforme pode ser observado na simulação apresentada na Figura 3(a), o modelo original (com recálculo, mas sem calibração da odometria) foi capaz de atingir a célula alvo com 
um erro final de 3,1156 centímetros. Nessa trajetória, o robô percorreu uma distância de 2,46 metros em 2 minutos e 16 segundos. Em contrapartida, durante o percurso houveram algumas colisões nos pontos indicados pelas setas amarelas e algumas invasões das áreas de segurança. Com a abordagem que combina o método UMBMark e o recálculo de rotas, o robô atingiu a célula objetivo com o menor erro final (1,4940 centímetros) e sem nenhuma colisão, conforme ilustrado na Figura 3(b). Apesar de ocorrer algumas invasões das áreas de segurança, a quantidade é bem menor que das demais abordagens. Além disso, nessa abordagem, o robô percorreu uma distância de 1,98 metros em 1 minuto e 56 segundos.

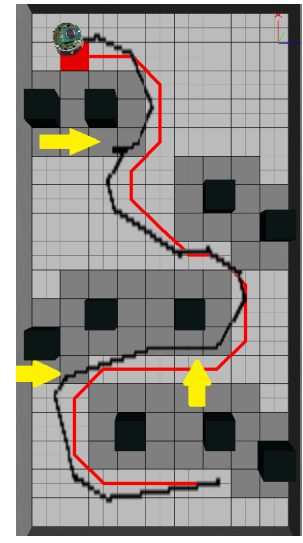

(a) Modelo original

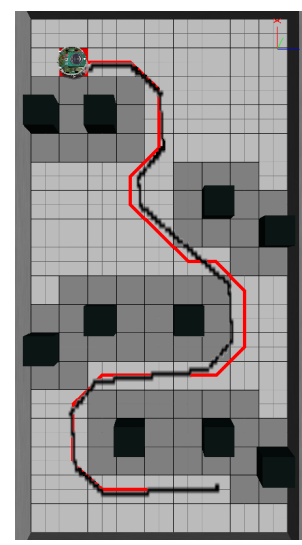

(b) Modelo refinado

Figura 3. Simulações baseadas no modelo apresentado em [Oliveira et al. 2015].

A partir das simulações, é possível concluir que o uso do método de calibração UMBMark melhorou significativamente o desempenho dos modelos de navegação investigados em relação ao posicionamento do robô no ambiente e à sua proximidade com a célula objetivo no final da simulação. Como esperado, devido a sua adaptabilidade durante a trajetória, o modelo com recálculo apresentou os melhores resultados. Portanto, a abordagem que combina os dois métodos (recálculo e calibração da odometria) é a mais adequada para a navegação de robôs autônomos a partir de métodos baseados na difusão de distâncias através de autômatos celulares.

\section{Conclusões}

A implementação do método de calibração UMBMark permitiu o refinamento do sistema de odometria adotado pelos modelos de navegação baseados em autômatos celulares. Seu uso possibilitou uma trajetória mais precisa e um menor erro final de posicionamento do robô em relação à célula objetivo. Quando esse método é combinado com o recálculo da rota proposto por [Oliveira et al. 2015], o modelo de navegação apresenta uma melhora significativa no seu desempenho, obtendo a melhor precisão entre as abordagens avaliadas, bem como uma trajetória mais próxima da idela e totalmente livre de colisões.

Atualmente, estão sendo investigadas possíveis alterações na regra do autômato celular visando a redução os movimentos de rotações e, consequentemente, o acúmulo de erros de odometria durante a navegação. Além disso, como trabalho futuro, pretende-se realizar experimentos com robôs e-puck para avaliar a eficiência dos modelos investigados 
em cenários reais, bem como aplicar o método de calibração na navegação de times de robôs a fim de analisar seu influência em modelos mais complexos.

\section{Agradecimentos}

Os autores agradecem à FAPEMIG, CAPES e CNPq pelo suporte financeiro.

\section{Referências}

Akbarimajd, A. and Hassanzadeh, A. (2011). A novel cellular automata based real time path planning method for mobile robots. J. of Engineering Research and Applications, 1(4):1262-1267.

Behring, C., Bracho, M., Castro, M., and Moreno, J. (2000). An algorithm for robot path planning with cellular automata. Int. Conf. on Cellular Automata for Research and Industry, pages 11-19.

Borenstein, J. and Feng., L. (1994). Umbmark a method for measuring, comparing, and correcting dead-reckoning errors in mobile robots. Technical report UM-MEAM-9422, University of Michigan.

Ferreira, G. B. S., Vargas, P. A., and Oliveira, G. M. B. (2014). An improved cellular automata-based model for robot path-planning. Conf. Towards Autonomous Robotic Systems, pages 25-36.

Ioannidis, K., Sirakoulis, G. C., and Andreadis, I. (2008). A cellular automaton collisionfree path planner suitable for cooperative robots. Panhellenic Conference on Informatics, pages 256-260.

Ioannidis, K., Sirakoulis, G. C., and Andreadis, I. (2011). A pathplanning method based on cellular automata for cooperative robots. Applied Artificial Intelligence, 25(8):721745 .

Lima, D. A. and Oliveira, G. M. (2017). A cellular automata ant memory model of foraging in a swarm of robots. Applied Mathematical Modelling, 47:551-572.

Marchese, F. (1996). Cellular automata in robot path planning. Proc. of the Workshop on Advanced Mobile Robots.

Marchese, F. M. (2002). A directional diffusion algorithm on cellular automata for robot path-planning. Future Generation Computer Systems, 18(7):983-994.

Oliveira, G. M. B., Vargas, P. A., and Ferreira, G. B. S. (2015). Investigating a cellular automata model that performs three distance diffusion on a robot path planning. Proc. of the European Conference on Artificial Life, pages 271-278.

Parker, L. E., Birch, B., and Reardon, C. (2003). Indoor target intercept using an acoustic sensor network and dual wavefrontpath planning. In Proceedings of IEEE International Symposium on Intelligent Robots and Systems, pages 278-283.

Shu, C. and Buxton, H. (1995). Parallel path planning on the distributed array processor. Parallel Computing, 21(11):1749-1767.

Tzionas, P. G., Thanailakis, A., and Tsalides, P. G. (1997). Collision-free path planning for a diamond-shaped robot using two-dimensional cellular automata. Trans. on Robotics and Automation, 13(2):237-250. 